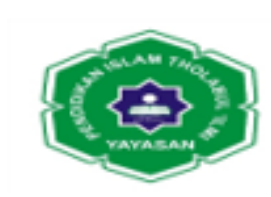

Jurnal Ilmiah METADATA

\title{
PENGARUH MOTIVASI DAN KEPEMIMPINAN TERHADAP PRESTASI KERJA PADA PT. PLN (PERSERO) UNIT INDUK PEMBANGUNAN II MEDAN
}

\author{
Saleh Sitompul \\ Sekolah Tinggi Ilmu Ekonomi, ITMI Medan \\ email : salehsitompul@gmail.com
}

\begin{abstract}
ABSTRAK
Sumber daya manusia merupakan hal terpenting yang dimiliki suatu organisasi dalam setiap kegiatan organisasi dimana manusia menjadi perencana, pelaku, dan penentu terwujudnya tujuan organisasi Motivasi adalah dorongan terhadap serangkain perilaku manusia pada pencapain tujuan Sedangkan Kepemimpinan adalah bagian yang dianggap penting dalam manajemen organisasi, Prestasi kerja adalah tingkat pelaksanaan tugas yang dapat dicapai oleh seeorang. Tujuan penelitian ini adalah untuk mengetahui pengaruh motivasi dan kepemimpinan terhadap prestasi kerja pada PT. PLN (Persero) Unit Induk Pembangunan II Medan. Sampel dalam penelitian ini adalah 30 orang pegawai tetap pada sub-sub bagian di kantor PT. PLN (Persero) Unit Induk Pembangunan II Medan. Teknik pengumpulan data dalam penelitian ini adalah daftar pertanyaan ( Quesioner ). Sedangkan teknik analisis data yang digunakan adalah regresi linear berganda, korelasi berganda, Uji t, Uji F dan determinasi. Secara parsial ada pengaruh motivasi terhadap prestasi kerja pada PT. PLN (Persero) Unit Induk Pembangunan II Medan dimana rhitung sebesar 0,213 sedangkan kepemimpinan juga berpengaruh terhadap prestasi kerja pegawai pada PT. PLN (Persero) Unit Induk Pembangunan II Medan dimana $r_{\text {hitung }}$ 0,287. Nilai korelasi berganda bersama-sama antara motivasi dan kepemimpinan terhadap prestasi kerja pegawai pada PT. PLN (Persero) Unit Induk Pembangunan II Medan diperoleh $R_{x 1 \times 2 y}=0,500$. Nilai yang positif tersebut mempunyai arti bahwa jika motivasi dan kepemimpinan ditingkatkan maka prestasi kerja pegawai akan meningkat.
\end{abstract}

Kata Kunci : Motivasi, Kepemimpinan, dan Prestasi Kerja

THE DETERMINE OF MOTIVATION AND LEADERSHIP ON WORK ACHIEVEMENT AT PT. PLN (PERSERO) UNIT INDUK PEMBANGUNAN II MEDAN

ABSTRACT 


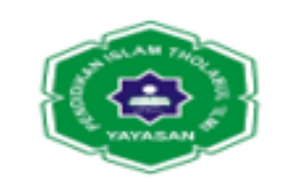

\section{Jurnal Ilmiah METADATA}

Human resources is the most important thing an organization has in every organizational activity where human beings become planners, actors, and determinants of the realization of organizational goals

Motivation is the impetus to a series of human behavior on the achievement of goals While Leadership is a part that is considered important in organizational management, Job performance is the level of execution of tasks that can be achieved by someone.

The purpose of this study was to determine the effect of motivation and leadership on work performance at PT. PLN (Persero) Development Unit II Medan. The sample in this research is 30 permanent employees in sub-sub section in office of PT. PLN (Persero) Development Unit II Medan. Data collection technique in this research is questionnaire (Quesioner). While the data analysis techniques used are multiple linear regression, multiple correlation, $t$ test, $F$ test and determination.

Partially there is influence of motivation to work performance at PT. PLN (Persero) Development Unit II Medan where rhitung of 0.213 while the leadership also affects the performance of employees at PT. PLN (Persero) Development Unit II Medan where rhitung 0.287. The value of multiple correlations between the motivation and leadership of employee performance at PT. PLN(Persero) Development Unit of Medan II obtained Rx $1 x 2 y=0,500$. This positive value means that if motivation and leadership are improved, employee performance will increase.

Keywords : Motivation, Leadership, and Job Performance

\section{PENDAHULUAN}

organisasi atau perusahaan yang berbentuk swasta maupun pemerintah, tentunya memiliki tujuan baik itu jangka pendek maupun jangka panjang yang hendak dicapai melalui aktivitas yang dilakukannya. Agar tujuan yang telah ditetapkan tercapai maka diperlukan perencanaan dan pengelolaan sumber daya manusia sebaikbaiknya.Istilah manejemen merujuk pada individu-individu yang ada dalam organisasi yang saling bekerja sama untuk mewujudkan tujuan organisasi.

Sumber daya manusia merupakan hal terpenting yang dimiliki suatu organisasi dalam setiap kegiatan organisasi dimana manusia menjadi perencana, pelaku, dan penentu terwujudnya tujuan organisasi. Oleh karena itu, agar organisasi dapat mencapai prestasi kerja yang maksimal diperlukan perlakuan yang adil dan memuaskan pada sumber daya manusia yang bekerja pada organisasi tersebut.

Prestasi kerja adalah merupakan suatu yang telah dihasilkan baik dalam bentuk produk maupun jasa dalam bentuk produk misalnya, prestasi menghasilkan produksi dalam jumlah tertentu yang lebih banyak dalam jumlah produksi normal, prestasi yang mencapai tingkat penjualan tertentu yang melampaui dari target yang ditetapkan perusahaan. 


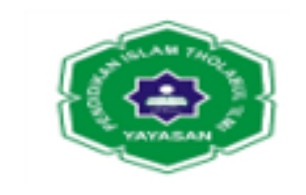

\section{Jurnal Ilmiah METADATA}

Dalam suatu organisasi atau perusahaan, kepemimpinan juga merupakan salah satu faktor penting karena Kepemimpinan adalah upaya mempengaruhi banyak orang melalui komunikasi untuk mencapai tujuan, cara mempengaruhi orang dengan petunjuk atau perintah, tindakan yang menyebabkan orang lain bertindak atau merespon dan menimbulkan perubahan positif, kekuatan dinamis yang penting yang memotivasi dan mengkoordinasikan organisasi dalam rangka mencapai tujuan, kemampuan untuk menciptakan rasa percaya diri dan dukungan diantara bawahan agar tujuan organisasi dapat tercapai.

\section{METODE PENELITIAN}

Lokasi yang menjadi tempat penelitian adalah pada PT.PLN (Persero) Unit Induk Pembangunan II., dengan judul penelitian "Pengaruh Motivasi dan Kepemimpinan Terhadap Prestasi Kerja". Waktu penelitian dimulai pada bulan April sampai bulan Juny 2017.

Populasi yang digunakan peneliti adalah pegawai tetap kantor PT.PLN (Persero) Unit Induk Pembangunan II. Dengan jumlah pegawai tetap yang berjumlah 30 orang.

Pengambilan sampel adalah proses memilih semua pegawai tetap yang bekerja pada PT.PLN (Persero) Unit Induk Pembangunan II sebanyak 30 orang.

Defenisi operasional bertujuan untuk melihat sejauh mana variabel-variabel yang ada didalam penelitian saling berkaitan dan dapat berpengaruh terhadap faktor lainnya. Definisi variabel memberikan arahan pada peneliti tentang tata cara mengukur suatu variabel. Dalam penelitian ini ada tiga variabel penelitian yaitu :

1) Variabel Motivasi (X1)

Motivasi adalah proses memengaruhi atau mendorong dari luar terhadap seseorang atau kelompok kerja agar mereka melaksanakan sesuatu yang telah ditetapkan.

2) Variabel Kepemimpinan $\left(X_{2}\right)$

Kepemimpinan adalah kemampuan menyakinkan dan mengerakkan orag lain agar mau bekerja sama dibawah kepemimpinannya sebagai suatu tim untuk mencapai suatu tujuan tertentu.

3) Variabel Prestasi Kerja (Y)

Prestasi kerja adalah tingkat pelaksanaan tugas yang dapat dicapai oleh seseorang, unit, atau divisi dengan menggunakan kemampuan yang ada dan batasan-batasan yang telah ditetapkan untuk mencapai tujuan organisasi perusahaan.

Pengukuran masing - masing variabel dalam penelitian ini adalah dengan menggunakan skala likert. Skala likert digunakan untuk mengukur sikap, pendapat, dan persepsi seseorang atau sekelompok orang tentang fenomena sosial. Dengan skala likert, maka variabel yang akan diukur dijabarkan menjadi indikator variabel. Kemudian indikator tersebut dijadikan sebagai titik tolak untuk 


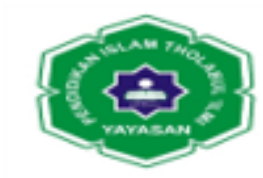

\section{Jurnal Ilmiah METADATA}

menyusun item-item instrumen yang dapat berupa pernyataan atau pertanyaan (Sugiyono,2010:93).

Sumber data diperoleh dari hasil wawancara, quesioner dari pegawai PT.PLN (Persero) Unit Induk Pembangunan II Medan Baru dan studi literatur berupa dokumen, jurnal yang berhubungan dengan penelitian.

\section{HASIL PENELITIAN DAN PEMBAHASAN}

A. Uji Validitas dan Reliabilitas

\section{Uji Validitas}

Untuk mendapatkan kualitas hasil penelitian yang bermutu dan baik sudah semestinya rangkaian penelitian harus dilakukan dengan baik. Uji validitas dilakukan untuk mengukur apakah data yang telah didapat setelah penelitian merupakan data yang valid dengan alat ukur yang digunakan (kuesioner). Bila koefisien korelasi (r) lebih besar dari $\mathrm{r}$ table $(0,361)$, maka pertanyaan tersebut dikatakan valid. Uji validitas dilakukan terlebih dahulu dengan memberikan kuesioner kepada 30 orang responden yang diambil dari luar sampel berdasarkan kriteria jenis kelamin laki-laki dan dilakukan di PT. PLN (Persero) Unit Induk Pembangunab II Medan. Pengujian validitas dilakukan dengan menggunakan program SPSS 23.3 dengan kriteria sebagai berikut:

Jika $\mathrm{r}$ hitung > $\mathrm{r}$ tabel, maka pertanyaan dinyatakan valid

Jika $\mathrm{r}$ hitung $<\mathrm{r}$ tabel, maka pertanyaan dinyatakan tidak valid.

\section{Tabel 1}

Uji Faliditas Variabel Motivasi (X1)

\begin{tabular}{|c|c|c|c|}
\hline $\begin{array}{c}\text { Perta } \\
\text { nyaa } \\
\mathrm{n}\end{array}$ & $\begin{array}{c}\text { Corrected } \\
\text { Item- } \\
\text { Total } \\
\text { Correlatio } \\
\mathrm{n}\end{array}$ & r-tabel & Keterangan \\
\hline 1 & .557 & 0,367 & Valid \\
\hline 2 & .686 & 0,367 & Valid \\
\hline 3 & .550 & 0,367 & Valid \\
\hline 4 & .627 & 0,367 & Valid \\
\hline 5 & .665 & 0,367 & Valid \\
\hline 6 & .593 & 0,367 & Valid \\
\hline
\end{tabular}

Sumber: Hasil Pengolahan SPSS 23 (2017)

Setelah di uji validitas variabel X1 (Motivasi ) item pertanyaan sebanyak 6 semua dinyatakan valid karena nilai corrected item-total correlation > 0,367. 


\section{Jurnal Ilmiah METADATA}

Tabel 2

Uji Validitas Variabel Kepemimpinan (X2)

\begin{tabular}{|c|r|c|c|}
\hline $\begin{array}{c}\text { Pert } \\
\text { any } \\
\text { aan }\end{array}$ & $\begin{array}{c}\text { Corrected } \\
\text { Item-Total } \\
\text { Correlation }\end{array}$ & r-tabel & Keterangan \\
\hline 1 & .614 & 0,367 & Valid \\
\hline 2 & .627 & 0,367 & Valid \\
\hline 3 & .672 & 0,367 & Valid \\
\hline 4 & .618 & 0,367 & Valid \\
\hline 5 & .378 & 0,367 & Valid \\
\hline
\end{tabular}

Sumber : Hasil Pengolahan SPSS 23 (2017)

Setelah di uji validitas variabel X2 (Kepemimpinan) item pertanyaan sebanyak 5 semua dinyatakan valid karena nilai corrected item-total correlation > 0,367.

Tabel 3

Uji Validitas Variabel Prestasi Kerja (Y)

\begin{tabular}{|c|r|r|c|}
\hline $\begin{array}{c}\text { Perta } \\
\text { nyaan }\end{array}$ & $\begin{array}{c}\text { Correcte } \\
\text { d Item- } \\
\text { Total } \\
\text { Correlati } \\
\text { on }\end{array}$ & r-tabel & Keterangan \\
\hline 1 & .592 & 0,367 & Valid \\
\hline 2 & .435 & 0,367 & Valid \\
\hline 3 & .399 & 0,367 & Valid \\
\hline
\end{tabular}

Sumber : Hasil Pengolahan SPSS 23 (2017)

Setelah di uji validitas variabel Y (Prestasi Kerja) item pertanyaan sebanyak 3 semua dinyatakan valid karena nilai corrected item-total correlation > 0,367.

\section{Reliabilitas}

Uji reliabilitas digunakan untuk melihat apakah alat ukur yang digunakan (kuesioner) menunjukkan konsistensi didalam mengukur gejala yang sama (Sugiyono, 2010:116). Pengujian dilakukan dengan menggunakan program SPSS. 14 butir pertanyaan yang sudah dinyatakan valid dalam uji validitas ditentukan reliabilitasnya dengan kriteria sebagai berikut:

Jika $r$ alpha positif atau $>r$ tabel maka pertanyaan reliabel

Jika $\mathrm{r}$ alpha negatif atau $<\mathrm{r}$ tabel maka pertanyaan tidak reliabel 


\section{Jurnal Ilmiah METADATA}

Tabel 4

Uji Reliabilitas Motivasi ( X1)

\begin{tabular}{|c|c|}
\hline \multicolumn{2}{|c|}{ Reliability Statistic } \\
\hline $\begin{array}{c}\text { Cronbach's } \\
\text { Alpha }\end{array}$ & N of Items \\
\hline .837 & 6 \\
\hline
\end{tabular}

Sumber : Hasil Pengolahan SPSS 23 (2017)

Berdasarkan output reliabilitas variabel X1 dapat diketahui bahwa variabel X1 adalah reliable dengan cronbachs Alpha adalah 0,837 atau > dari 0,70. Berdasarkan hasil ini juga dapat disimpulkan bahwa item pertanyaan kuesioner sudah memiliki reliabilitas yang tinggi.

\section{Tabel 5}

Uji Reliabilitas Kepemimpinan (X2)

Reliability Statistic

\begin{tabular}{|c|c|}
\hline $\begin{array}{c}\text { Cronbach's } \\
\text { Alpha }\end{array}$ & $\mathrm{N}$ of Items \\
\hline .798 & 5 \\
\hline
\end{tabular}

Sumber : Hasil Pengolahan SPSS 23 (2017)

Berdasarkan output reliabilitas variabel X2 dapat diketahui bahwa variabel X2 adalah reliable dengan cronbachs Alpha adalah 0,798 atau > dari 0,70. Berdasarkan hasil ini juga dapat disimpulkan bahwa item pertanyaan kuesioner sudah memiliki reliabilitas yang tinggi.

\section{Tabel 6}

Uji reliabilitas Prestasi Kerja (Y)

Reliability Statistic

\begin{tabular}{|c|c|}
\hline $\begin{array}{c}\text { Cronbach's } \\
\text { Alpha }\end{array}$ & N of Items \\
\hline 724 & 3 \\
\hline
\end{tabular}

Sumber : Hasil Pengolahan SPSS 23 (2017) 


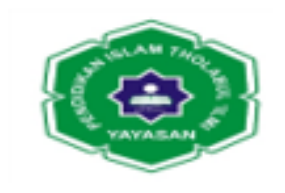

\section{Jurnal Ilmiah METADATA}

Berdasarkan output reliabilitas variabel Y dapat diketahui bahwa variabel Y adalah reliable dengan cronbachs Alpha adalah 0,724 atau > dari 0,70.

Berdasarkan hasil ini juga dapat disimpulkan bahwa item pertanyaan kuesioner sudah memiliki reliabilitas yang tinggi.

\section{B. Uji Asumsi Klasik}

Uji Asumsi Klasik digunakan untuk melihat apakah suatu model layak atau tidak layak digunakan dalam penelitian. Uji Asumsi Klasik yang digunakan dalam penelitian ini adalah sebagai berikut:

\section{Uji Normalitas}

Uji normalitas adalah untuk mengetahui apakah distribusi data mengikuti atau mendekati distribusi normal. Uji normalitas dilakukan dengan menggunakan pendekatan Kolmogorov Smirnov. Dengan menggunakan tingkat signifikansi 5\% maka jika nilai Asymp.sig. (2-tailed) diatas, nilai signifikan 5\% artinya variabel residual berdistribusi normal.

Salah satu cara untuk melihat normalitas adalah dengan melihat grafik histrogram dan grafik normal plot yang membandingkan antara dua absorvasi dengan distribusi yang mendekati distribusi normal.

\section{Uji Heteroskedastisitas}

Tujuan uji heteroskedastisitas adalah untuk mengetahui apakah dalam sebuah model regresi terjadi ketidaksamaan varian dari residual antara satu pengamatan dengan pengamatan yang lain. Model regresi yang baik adalah yang Homoskedastisitas atau tidak terjadi heteroskedastisitas. yaitu :

Ada beberapa cara untuk mendekati ada atau tidaknya heteroskedastisitas

\section{a. Metode Grafik}

Dasar analisis adalah jika tidak ada pola yang jelas, serta titik-titik menyebar diatas dan dibawah angka 0 pada sumbu Y, maka tidak terjadi Heteroskedastisitas, sedangkan jika ada pola tertentu seperti titik-titik yang ada membentuk pola tertentu yang teratur maka mengindikasikan telah terjadi heterokedastisitas.

\section{b. Uji Glesjer}

Glejser mengusulkan untuk meregresi nilai absolut residual terhadap variabel independen. Jika variabel independen signifikan secara statistik mempengaruhi variabel dependen maka ada indikasi terjadi heteroskedastisitas.

\section{Uji Multikolinearitas}

Uji Multikolinearitas bertujuan untuk mendeteksi ada atau tidaknnya gejala multikolinearitas pada data dapat dilakukan dengan melihat nilai tolerance value dan Varians Inflation factor (VIF). Dengan kriteria sebagai berikut : 


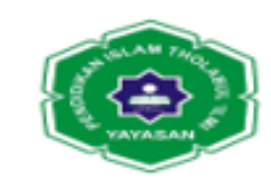

\section{Jurnal Ilmiah METADATA}

1. Apabila VIF $>5$ maka diduga mempunyai persoalan Multikolinearitas.

2. Apabila VIF $<$ dari 5 maka tidak terdapat Multikolinearitas.

3. Apabila tolerance $<0,1$ maka diduga mempunyai persoalan heteroskedastisitas.

4. Apabila tolerance $>0,1$ maka tidak terd apat multikolinearitas.

\section{Analisis Deskriptif Responden}

Metode analisis deskriptif adalah cara merumuskan dan menafsirkan data yang ada sehingga memberikan gambaran yang jelas melalui pengumpulan, penyusunan, penganalisisan data, sehingga dapat diketahui gambaran umum dari objek yang diteliti. Data utama dalam penelitian ini adalah informasi dari responden dan pernyataan-pernyataan untuk mendapatkan informasi yang dibutuhkan dalam menganalisis masalah penelitian yang dirumuskan.

Instrumen yang digunakan dalam penelitian ini adalah daftar pertanyaan (kuesioner). Jumlah pertanyaan seluruhnya adalah 14 butir pertanyaan yakni 6 butir pertanyaan untuk variabel Motivasi (X1), 5 butir pertanyaan untuk variabel Kepemimpinab (X2) dan 3 butir pertanyaan untuk variabel Prestasi Kerja (Y).

Analisis deskriptif pada penelitian ini diperoleh dari penyebaran kuesioner kepada 30 orang responden orang responden pegawai PT. PLN (Persero) Unit Induk Pembangunan II Medan.

Kuesioner berisikan deskripsi responden dan jawaban atas pertanyaan yang diberikan. Karateristik responden dalam penelitian ini adalah berdasarkan jenis kelamin, usia, pendidikan, dan lama bekerja.

\section{Analisis Statistik Regresi Linear Berganda}

Metode analisis regresi berganda digunakan untuk mengetahui berapa besar pengaruh variabel bebas Motivasi dan Kepemimpinan) terhadap variabel terikat (Prestasi Kerja). Data diolah secara statistik untuk keperluan analisis dan pengujian hipotesis dengan menggunakan alat bantu program SPSS 23 for windows. Adapun bentuk umum persamaan regresi yang digunakan adalah sebagai berikut :

$\mathbf{Y}=\boldsymbol{\alpha}+\mathbf{b} 1 \mathbf{X}_{1}+\mathbf{b}_{2} \mathbf{X}_{2}+\mathbf{e}$

$\mathrm{Y}=$ Prestasi Kerja

Dimana :

$\mathrm{X}_{1}=$ Motivasi

$\mathrm{X}_{2}=$ Kepemimpinan

$\alpha=$ Konstanta

$\mathrm{b}_{1}, \mathrm{~b}_{2}=$ Koefisien regresi

$\mathrm{e}=$ Standar eror

Berdasarkan pengujian menggunakan SPSS versi 23 for windows, maka hasil persamaan regresi linear berganda dapat dilihat pada Tabel berikut ini :

Tabel 4.17 Hasil Regresi Linier Berganda 


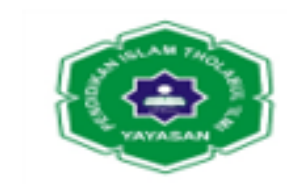

\section{Jurnal Ilmiah METADATA}

Berdasarkan Tabel 4.17 diketahui pada kolom kedua (unstandardized Coefficients) bagian B diperoleh nilai b1 variabel Motivasi sebesar 0.213 nilai b2 dan variabel Kepemimpinan sebesar 0.287 dan nilai konstanta (a) adalah 1.335, maka diperoleh persamaan regresi linier berganda sebagai berikut :

$$
\mathbf{Y}=\mathbf{1 . 3 3 5}+\mathbf{0 . 2 1 3} \mathrm{X}_{1}+\mathbf{0 . 2 8 7} \mathrm{X}_{2}
$$

Berdasarkan persamaan diatas maka dapat diuraikan sebagai berikut :

1. Konstanta $(a)=1,335$ ini menunjukkan bahwa jika variabel Motivasi dan Kepemimpinan dianggap konstan maka tingkat variabel Prestasi Kerja Pegawai (Y) PT. PLN (persero) Unit Induk Pembangunan II Medan sebesar 1.335

2. Koefisien b1 $\left(\mathrm{X}_{1}\right)=0.213$ menunjukkan bahwa variabel Motivasi berpengaruh positif Prestasi Kerja atau dengan kata lain jika variabel Motivasi ditingkatkan maka Prestasi Keja pegawai akan bertambah sebesar 0.213

3. Koefisien b2 $\left(\mathrm{X}_{2}\right)=0.287$, menunjukkan bahwa variabel Kepemimpinan berpengaruh secara positif terhadap Prestasi Kerja. Dengan kata lain jika variabel Kepemimpinan ditingkatkan maka Prestasi Kerja akan bertambah sebesar 0.287.

\section{E. Pengujian Hipotesis}

\section{Uji Signifikansi Simultan (Uji F)}

Pengujian ini dilakukan untuk melihat secara bersama-sama pengaruh atau hubungan positif dan signifikan variabel bebas $\left(\mathrm{X}_{1}, \mathrm{X}_{2}\right)$ berupa Motivasi dan Kepemimpina terhadap variabel terikat $(\mathrm{Y})$ berupa Prestasi Kerja pada PT. PLN (persero) Unit Induk Pembangunan II Medan.

$\mathrm{H}_{0}: \mathrm{b}_{1}=\mathrm{b}_{2}=0$, Artinya secara serentak Motivasi dan Kepemimpinan berpengaruh positif dan tidak signifikan terhadapPrestasi Kerja Pegawai.

$\mathrm{H}_{0}: \mathrm{b}_{1} \neq \mathrm{b}_{2} \neq 0$, Atinya secara serentak Motivasi dan Kepemimpinan berpengaruh positif dan signifikan terhadap Prestasi Kerja Pegawai.

Untuk menentukan nilai $\mathrm{F}$, maka diperlukan adanya derajat bebas pembilang dan derajat bebeas penyebut, dengan rumus sebagai berikut :

df (Pembilang) $=\mathrm{k}-1$

$\mathrm{df}($ Penyebut $)=\mathrm{n}-\mathrm{k}$

keterangan :

$\mathrm{n}=$ Jumlah sampel penelitian

Pada penelitian ini diketahui jumlah sampel (n) 30 dan jumlah keseluruhan variabel (k) adalah 3, sehingga diperoleh :

1. $\mathrm{df}$ (pembilang) $=3-1=2$

2. $\operatorname{df}($ penyebut $)=30-3=27$ 


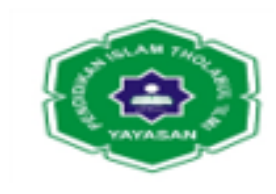

\section{Jurnal Ilmiah METADATA}

Nilai F hitung akan diperoleh dengan menggunakan bantuan SPSS 23 for windows, kemudian akan dibandingkan dengan $F$ tabel pada tingkat $\alpha=5 \%$ $(2: 45)=3.11$ dengan kriteria uji sebagai berikut :

$$
\begin{gathered}
\mathrm{H}_{0} \text { diterima jika } \mathrm{F} \text { hitung }<\mathrm{F} \text { Tabel pada } \alpha=5 \% \\
\mathrm{H}_{0} \text { ditolak jika } \mathrm{F} \text { hitung }>\mathrm{F} \text { tabel pada } \alpha=5 \%
\end{gathered}
$$

Dilihat hasil Uji F secara simultan, dan diperoleh nilai Fhitung $=65,522$ dengan tingkat signifikansi 0,000. Sedangkan nilai $F$ tabel $=2,96$ Nilai $F$ hitung > Ftabel $(65,522>2,96)$ dan tingkat signifikansi $(0.000<0,05)$ dengan hipotesis $\mathrm{H}_{0}$ dan $\mathrm{H}_{\mathrm{a}}$ diterima sehingga dapat disimpulkan bahwa variabel bebas yaitu Motivasi (X1) dan Kepemimpinan (X2) secara bersama-sama berpengaruh positif dan signifikan terhadap variabel Prestasi Kerja pada PT. PLN (persero) Unit Induk Pembangunan II $\operatorname{Medan}(\mathrm{Y})$.

\section{Uji Signifikansi Parsial (Uji-t)}

Uji-t dilakukan untuk menguji secara parsial apakah Motivasi (X1) Kepemimpinan (X2) secara parsial atau masing-masing berpengaruh signifikan terhadap Prestasi Kerja PT. PLN (persero) Unit Induk Pembangunan II Medan (Y). Hasil uji t dapat dilihat pada Tabel 4.19 sebagai berikut ini :

1. Variabel Motivasi adalah 3.606 dengan tingkat signifikansi 0.001 dan nilai t tabel pada alpha $5 \%$ dan df $1=27$ adalah 2.771 variabel Motivasi berpengaruh secara positif dan signifikan terhadap Prestasi Kerja PT. PLN (persero) Unit Induk Pembangunan II Medan. Hal ini terlihat dari nilai signifikansi $0.001<0.05$. nilai $\mathrm{t}$ hitung (3.606) > t tabel 2.771 artinya jika Motivasi ditingkatkan maka Prestasi Kerja akan meningkat.

2. Variabel Kepemimpinan adalah 3.828 dengan tingkat signifikansi 0.001 dan nilai $\mathrm{t}$ tabel pada alpha $5 \%$ dan df1 $=27$ adalah 2.771 variabel Kepemimpinan berpengaruh secara positif dan signifikan terhadap Prestasi Kerja PT. PLN (persero) Unit Induk Pembangunan II Medan, hal ini terlihat dari nilai signifikansi 0.001 $<$ 0.05. nilai thitung (3.828) > tabel (2.771) jika kondisi Kepemimpinan ditingkatkan menjadi lebih baik maka kinerja karyawan akan meningkat.

\section{Ppengujian Koefisien Determinasi $\left(\mathbf{R}^{2}\right)$}

Pengujian Koefisien determinan digunakan untuk mengukur seberapa besar kontribusi variabel bebas (Motivasi dan Kepemimpinan) terhadap variabel terikat (Prestasi Kerja). Koefisien determinasi berkisar antara nol sampai satu $\left(0 \leq \mathrm{R}^{2} \geq 1\right)$.

Jika $\mathrm{R}^{2}$ semakin besar atau mendekati satu, maka dapat dikatakan bahwa pengaruh variabel bebas (X1) yaitu Motivasi, (X2) yaitu Kepemimpinan adalah besar 


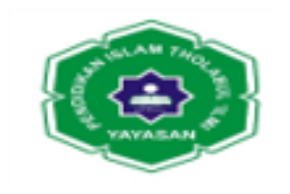

Jurnal Ilmiah METADATA

terhadap variabel terikat (Y) yaitu Prestasi Kerja. Hal ini berarti model yang digunakan semakin kuat untuk menerangkan pengaruh variabel bebas terhadap variabel terikat dan demikian sebaliknya.

Dapat diketahui bahwa :

1. Nilai $\mathrm{R}$ sebesar 0.911 sama dengan $91.1 \%$ berarti hubungan antara variabel Motivasi (X1) dan Kepemimpinan (X2) terhadap variabel Prestasi Kerja (Y) sebesar $91.1 \%$ artinya hubungannya erat.

2. Nilai Adjusted $R$ Square 0.817 berarti $81,7 \%$ prestasi kerja dapat dijelaskan oleh variabel motivasi dan Variabel kepemimpinan. Sedangkan sisanya $18,3 \% \%$ dapat dijelaskan oleh faktor-faktor lain yang diteliti dalam penelitian ini seperti gaya kepemimpinan, motivasi, disiplin kerja, dan lain sebagainya.

3. Standard Error of the Estimate artinya mengukur variasi dari nilai yang diprediksi. Nilai Standard Error of the Estimate 504.

\section{F. Pembahasan}

\section{Pengaruh Motivasi Terhadap Prestasi Kerja}

Berdasarkan hasil penelitian diatas mengenai pengaruh antara motivasi

Terhadap prestasi kerja pada PT. PLN (Persero) Unit Induk Pembangunan II Medan. Yang menyatakan bahwa $t_{\text {hitung }}>\mathrm{t}_{\text {tabel, }}$ 3,606 $>2,771 \mathrm{~d}$ an $\mathrm{t}_{\text {hitung }}$ berada di daerah tolak $\mathrm{H}_{\mathrm{o}}$ sehingga $\mathrm{H}_{\mathrm{a}}$ diterima ( $\mathrm{H}_{\mathrm{o}}$ ditolak), sehingga dapat disimpulkan bahwa ada pengaruh yang signifikan antara motivasi terhadap prestasi kerja pada PT. PLN (Persero) Unit Induk Pembangunan II Medan.

Berdasarkan nilai regresi sebesar 0,213 membuktikan bahwa Motivasi berpengaru positif terhadap Prestasi Kerja, hal ini menandakan bahwa apabila motivasi meningkatmaka prestasi kerja perusahaan juga akan meningkat.

Motivasi berpengaruh signifikan terhadap prestasi kerja disebabkan memiliki signifikan sebesar 0,001 $<0,05$ hal ini berarti "Motivasi berpengaruh signifikan terhadap Prestasi Kerja."

Dan hal ini sesuai dengan penelitian terdahulu oleh hartati purba (2016) dimana hasil penelitiannya menunjukkan bahwa motivasi dan kepemimpian berpengruh terhadap prestasi kerja pegawai pada PT. BPKP ( Badan Pengawasan Pembangunan ) Propinsi Sumatra Utara, dan dapat disimpulkan bahwa saat ini motivasi sangat dibutuhkan dan sangat berperan dalam setiap organisasi.

\section{Pengaruh Kepemimpinan terhadap Prestasi Kerja}

Pada variabel kepemimpinan 3,828 dengan tingkat signifikan 0,001 dan nilai $\mathrm{t}_{\text {tabel }}$ pada alpha 5\% dan df $1=27$ adalah 2,771 variabel kepemimpinan berpengruh secara positif dan signifikan terhadap prestasi kerja pada PT. PLN (Persero ) Unit Induk Pembangunan II Medan, hal ini terlihat dari nilai signifikan 0,001 $<0.05$. Nilai $t_{\text {hitung }}(3,828)>t_{\text {tabel }}(2,771)$ jika kondisi kepemimpinan ditingkatkan menjadi lebih baik 


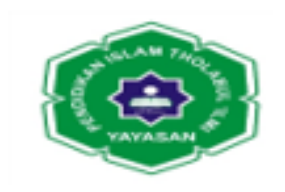

\section{Jurnal Ilmiah METADATA}

maka prestasi kerja pegawai akan meningkat. Hal ini juga sesuai dengan hasil penelitian terdahulu yang diteliti oleh Rindi Cahaya Indra (2014) dimana hasil penelitiannya menunjukkan bahwa kepemimpinan berpengaruh terhadap efisiensi prestasi kerja pegawai pada PT. PDAM Tirta Nadi Medan. Karena dengan kepemimpinan hubungan yang baik akan terjalin dalam organisasi atau dalam suatu pekerjaan akan mampu meningkatkan prestasi kerja pegawai

\section{Pengaruh Motivasi dan Kepemimpinan Terhadap Prestasi Kerja}

Berdasarkan hasil penelitian diatas mengenai pengaruh Motivasi dan Kepemimpinan secara bersama-sama terhadap Prestasi Kerja pada PT. PLN (Persero) Unit Induk Pembangunan II Medan yang menyatakan bahwa $F_{\text {hitung }}>F_{\text {tabel, }}(65,522)>($ 2,96) dan $t_{\text {hitung }}$ bereada di daerah tolak $\mathrm{H}_{\mathrm{o}}$ sehingga $\mathrm{H}_{\mathrm{a}}$ diterima $\left(\mathrm{H}_{\mathrm{o}}\right.$ ditolak), nilai signifikan 0,001<0,005 hal ini berarti " Motivasi dan Kepemimpinan secara bersamasama berpengaruh signifikan terhadap Prestasi Kerja pada PT. PLN (Persero) Unit Induk Pembangunan II Medan. Hal ini juga berkaitan dengan hasil penelitian terdahulu yang diteliti oleh Imam Fauzi menunjukkan bahwa motivasi dan kepemimpinan bersama-sama berpengruh kepada prestasi kerja pegawai pada PT.Perkebunan Nusantara IV. Secara Parsial maupun simultan pemberian motivasi kerja yang baik maka gairah kerja pegawai akan meningkat dan hasil kerja akan optimal sesuai dengan keinginan perusahaan.

\section{KESIMPULAN}

Berdasarkan hasil penelitian dan pembahasan yang dilakukan oleh penulis mengenai pengeruh Motivasi dan Kepemimpinan terhad ap Prestasi Kerja pada PT.PLN (Persero) Unit Induk Pembangunan II Medan maka dapat ditarik kesimpulan sebagai berikut :

1. Berdasarkan dari hasil penelitian dapat dilihat hasil Uji F secara simultan, dan diperoleh nilai Fhitung $=65,522$ dengan tingkat signifikansi 0,001. Sedangkan nilai $\mathrm{F}$ tabel $=2,96$ Nilai $\mathrm{F}$ hitung $>$ Ftabel $(65,522>2,96)$ dan tingkat signifikansi $(0.000<0,05)$ dengan hipotesis $\mathrm{H}_{0}$ dan $\mathrm{H}_{\mathrm{a}}$ diterima sehingga dapat disimpulkan bahwa variabel bebas yaitu Motivasi (X1) dan Kepemimpinan (X2) secara bersamasama berpengaruh positif dan signifikan terhadap variabel Prestasi Kerja pada PT. PLN (persero) Unit Induk Pembangunan II Medan (Y).

2. Berdasarkan dari hasil penelitian bahwa Variabel Motivasi adalah 3.606 dengan tingkat signifikansi 0.001 dan nilai t tabel pada alpha $5 \%$ dan df $1=27$ adalah 2.771 variabel Motivasi berpengaruh secara positif dan signifikan terhadap Prestasi Kerja PT. PLN (persero) Unit Induk Pembangunan II Medan. Hal ini terlihat dari nilai signifikansi $0.001<0.05$. nilai $\mathrm{t}$ hitung (3.606) $>\mathrm{t}$ tabel 2.771 artinya jika Motivasi ditingkatkan maka Prestasi Kerja akan meningkat. Dan juga Variabel 


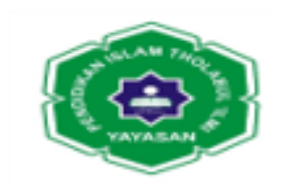

\section{Jurnal Ilmiah METADATA}

Kepemimpinan adalah 3.828 dengan tingkat signifikansi 0.001 dan nilai $t$ tabel pada alpha $5 \%$ dan df $1=27$ adalah 2.771 variabel Kepemimpinan berpengaruh secara positif dan signifikan terhadap Prestasi Kerja PT. PLN (persero) Unit Induk Pembangunan II Medan, hal ini terlihat dari nilai signifikansi $0.001<0.05$. nilai thitung (3.828) > ttabel (2.771) jika kondisi Kepemimpinan ditingkatkan menjadi lebih baik maka kinerja karyawan akan meningkat.

3. Dari hasil nilai $\mathrm{R}$ sebesar 0.911 sama dengan $91.1 \%$ berarti hubungan antara variabel Motivasi (X1) dan Kepemimpinan (X2) terhadap variabel Prestasi Kerja (Y) sebesar $91.1 \%$ artinya hubungannya erat. Nilai Adjusted $R$ Square 0.817 berarti $81,7 \%$ prestasi kerja dapat di jelaskan oleh variabel motivasi dan Variabel kepemimpinan. Sedangkan sisanya $18,3 \% \%$ dapat dijelaskan oleh faktor-faktor lain yang diteliti dalam penelitian ini seperti gaya kepemimpinan, motivasi, disiplin kerja, dan lain sebagainya.

\section{DAFTAR PUSTAKA}

Anwar PrabuMangkunegara, 2009, Manajemen Sumber Daya Manusia Perusahaan, Bandung, PT.Remaja Rosdakarya.

Hamzah B. Uno, 2011,Teori Motivasi dan Pengukurannya.Ed.Cet.8, Jakarta: Bumi Akasara.

Hasibuan, Malayu, 2011, Manajemen:Dasar, Pengertian, dan Masalah, Ed.Revisi, Cet.9, Jakarta, Bumi Akasara.

Irham Fahmi, 2014, Manajemen Kepemimpinan Teori dan Aplikasi, Penerbit ALFABETA, CV.

Sadili Samsudin, 2006, Manajemen Sumber Daya Manusia, Penerbit Pustaka Bandung.

Siagian Sondang, 2010, Teori dan Praktek Kepemimpinan. Rineka Cipta Jakarta.

Sopiah, 2008, Perilaku Organisasional .Penerbit : ANDI OFFSET.

Sugiyono, 2010, Metode Penelitian Kuantitatif, Kualitatif dan $R \& G$, Bandung.

Usman Husaini, 2013,Manajemen Teori, Praktik, dan Riset Pendidikan. Dietrbitkan oleh PT. Ikrar Mandiriabadi.

VeitzhalRivai, 2013, Pemimpin dan Kepemimpinan Dalam Organisasi,PT.RajaGrafindo Persada, Jakarta. 


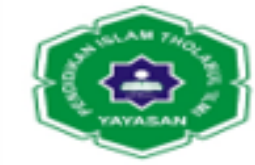

\section{Jurnal Ilmiah METADATA}

Wibowo, 2016, Kepemimpinan, Pemahaman Dasar, Pandangan Konvensional, Gagasan Kontemporer, PT. RajaGrafindo Persada, JAKARTA. 